\title{
Analysis of readymade readers and near-inter-pupillary distance for presbyopic patients in optometric practice in Cape Town, South Africa
}

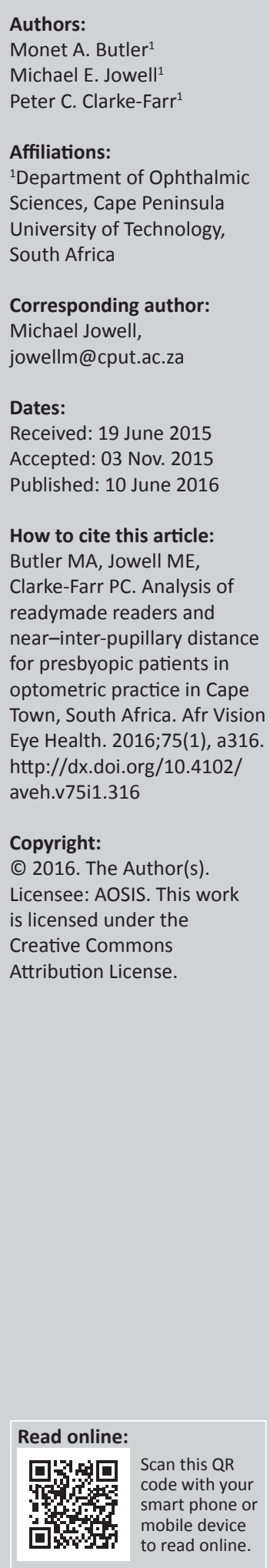

Purpose and background: This study has particular significance in ophthalmic dispensing as well as for optometry when considering the use of readymade readers (RMRs) both in private practice and in the public health sector. This study investigated firstly whether the optical centre (OC) distance for a sample of RMRs correlates with the near-inter-pupillary distance (near-IPD) for presbyopic patients, whether induced prism occurs with convergence when reading and whether RMR lenses are free of optical strain.

Methods: Near-IPDs (measured by a single individual) were obtained from record cards of 1080 patients ( 540 male patients and 540 female patients). The OC distances were determined for 60 RMRs using a Nikon PL-2 screen vertometer, and induced prismatic effects were calculated for vertical and horizontal meridians. The presence of optical strain was analysed and graded using crossed polarised filters (within a polariscope).

Results: The measured average near-IPD was $59.04 \mathrm{~mm}$ (s.d. \pm 2.87 ) for the 540 female patients and $61.59 \mathrm{~mm}$ (s.d. \pm 3.08 ) for the 540 male patients. The measured average RMR OC distance was $64.49 \mathrm{~mm}$ (s.d. \pm 3.74 ) for female patients and $62.77 \mathrm{~mm}$ (s.d. \pm 1.57 ) for male patients. Based on the mean near-IPD and the corresponding RMR OC distance, the average horizontal prismatic effect found in RMRs designed for female patients with induced prism was $0.11 \mathrm{pd}$ base-out (5.06 mm outwards) and $0.04 \mathrm{pd}$ base-in (1.26 mm inwards). For male RMRs, this was $0.03 \mathrm{pd}$ base-out (1.32 $\mathrm{mm}$ outwards) and $0.02 \mathrm{pd}$ base-in (1.28 $\mathrm{mm}$ inwards). When comparing RMR distances with near-IPDs, $t=-7.87, p<0.001$ for female patients and $t=-3.69, p<0.001$ for male patients. The average vertical differential prismatic effect for female patients was $0.67 \mathrm{pd}$ and it was $0.68 \mathrm{pd}$ for male patients. Optical strain was observed in $66.67 \%$ and $56.67 \%$ of RMR lenses for female and male patients, respectively. The strain pattern was found to be most severe in the inferior temporal periphery for 34 RMRs for female patients and for 20 RMRs for male patients, followed by the inferior nasal periphery for 27 and 18 lenses (RMRs) for male and female patients, respectively.

Conclusion: Most RMRs were found to be within international standard tolerances for horizontally induced prismatic effects, but $10 \%$ of female and $36.67 \%$ of male RMRs had vertical prismatic effects, which exceeded international standards. Significant optical strain was found in the inferior nasal reading portion of the RMRs.

\section{Introduction}

Functional presbyopia is estimated to be uncorrected in 517 million people globally, half of whom suffer from this visual impairment (1.04 billion). ${ }^{1}$ Underdeveloped countries bear the burden of uncorrected presbyopia with 410 million (94\%) of those uncorrected presbyopes unable to perform basic near-work tasks. ${ }^{1}$ Functional presbyopia creates significant socio-economic burdens and has a high impact on occupational productivity and vision-related quality of life. ${ }^{2}$ To reduce the number of uncorrected presbyopic people, inexpensive, mass-produced and readily available corrections are required. Readymade readers (RMRs), mass-produced spectacles for near-vision with both eyes having equal spherical power and a fixed centration distance, have been shown to be an effective treatment in the absence of custom-made spectacles. ${ }^{3,4}$ RMRs are easily accessible and affordable without the need of a prescription, which makes them ideal as a spare pair of glasses for middle- to high-income patients and as the primary presbyopic correction in low-income areas. However, the optical quality of these spectacles has been found to be below standard. $5,6,7$ It is important to note that the dispensing of RMRs should always be preceded by 
a comprehensive eye examination in order to rule out the presence of any ocular abnormality or pathology.

Two important criteria for checking the optical quality of RMRs are the possible induced horizontal and vertical prismatic effects (anisophoria) as well as the presence of optical strain in the lenses. RMRs may sometimes be unsatisfactory because patients' inter-pupillary distances (IPD) and near-inter-pupillary distances (NIPD) differ, that is, the geometrical distances between the centres of the pupils $^{8}$ are different from the RMR optical centre (OC) distances. ${ }^{9}$ The consequence would be unwanted horizontal prismatic effects. ${ }^{10}$ The amount of induced prismatic effect depends on the power of the lens and the distance between the OC and the visual axis, as determined by Prentice's rule. ${ }^{11}$ These induced prismatic effects can cause disruptions of binocular vision and may result in eye fatigue and headaches ${ }^{12}$ as well as mild vertigo or dizziness, micropsia, macropsia, blurred vision and diplopia. ${ }^{5}$ Such effects would be expected to manifest when wearing the spectacles over a prolonged period of time. Horizontally induced prismatic effect is probably more common in RMRs than custom-made spectacles because they have a set OC distance, which may differ between frame makes and sizes. However, NIPDs vary greatly between people and have been found to differ between genders, age, race and ethnicities ${ }^{8,13,14}$ and monocular IPDs are often asymmetric. RMRs once manufactured may not have their optical centration distance matching those of the NIPD of the population, who make use of these spectacles. If the mean OCs differ from the mean NIPD of patients, then there would be an increased chance of visual discomfort because of induced horizontal prism.

Vertical centration errors, which occur when the OC of a lens is vertically displaced compared to the other lens in a spectacle, are of more concern because wearers are only able to tolerate small amounts of unintended vertical prism and, for example du Toit et al..$^{9}$ studying the tolerance to prism induced by readymade spectacles, in both distant and near-vision, found that patients would comfortably tolerate $\leq 1.0 \mathrm{pd}$ in the horizontal (base-in or base-out) but only $\leq 0.5 \mathrm{pd}$ in the vertical. The amount of induced differential prism that an RMR may carry should comply with one of the following standards: British Standards Institute (B.S.2738) cited in Jalie, ${ }^{11}$ the American National Standards Institute (ANSI) $)^{15}$ or the International Organization for Standardization $\left(\right.$ ISO 16034:2002) ${ }^{16}$ (Table 1). From Table 1, it can be seen that the most lenient tolerance would be $0.66 \mathrm{pd}$ horizontal and 0.33 pd vertical.

Optical strain is of more importance in near-vision spectacles compared to distance vision spectacles because the wearer usually views through the inferior nasal areas of the lens, which is where strain may be at its greatest. According to Jalie, ${ }^{11}$ strain of an ophthalmic lens most probably occurs from external pressure compressing the lenses in the spectacle frame, most likely because the lens is too large and is glazed too tightly in the spectacle frame. Strain is traditionally observed using a polariscope, although Brian et al. ${ }^{17}$ suggest that in developing countries, strain can also be measured using a Geneva lens measure (lens clock).

\section{Methodology}

The aim of this study was therefore to determine whether the near-IPDs for a sample of patients from a private optometric practice in the Western Cape, South Africa, correlated with the OC distance of RMRs available to these patients. In order to reach this aim, the study objectives were to determine the near-IPDs for the sample of patients, to calculate any induced horizontal and vertical prismatic effects and to assess the presence of optical strain in the lenses.

This study was carried out in a private optometric practice in Sea Point, Cape Town described as a middle- to highincome suburb consisting of $70 \%$ white (Caucasian) population $^{18}$ (City of Cape Town, Census 2011). A minimum sample size of 1067 patient records was calculated ${ }^{19}$ to be representative of the Western Cape population of 5287863 people ${ }^{20}$ for a confidence level of $95 \%$ and confidence interval (CI) of $3 \mathrm{~mm}$. An experimental quantitative design method was used in the data collection of patients' near-IPD, the RMR OC distances, horizontal and vertical prism and the analysis of strain patterns. The data were analysed using Excel 2011 for Mac.

The sample data were collected from record cards for 540 female and 540 male patients between the ages of 40 and 74 years. For each cohort (female and male patients), the measurement data were randomly selected from patient record cards where SA had measured the near-IPD, a single Health Professions Council of South Africa registered optometrist, who used the same technique for each measurement. These data were used to determine the

TABLE 1: International standards and tolerances.

\begin{tabular}{|c|c|c|c|c|c|}
\hline \multirow[t]{2}{*}{ Standard type } & \multirow[t]{2}{*}{ Addition power } & \multicolumn{2}{|c|}{ Horizontal meridian } & \multicolumn{2}{|c|}{ Vertical meridian } \\
\hline & & $\begin{array}{c}\text { Tolerance } \\
\text { (pd base-in and base-out) }\end{array}$ & $\begin{array}{l}\text { Decentration } \\
(\mathrm{mm})\end{array}$ & $\begin{array}{c}\text { Tolerance } \\
\text { (pd base-up and base-down) }\end{array}$ & $\begin{array}{l}\text { Decentration } \\
(\mathrm{mm})\end{array}$ \\
\hline \multirow[t]{2}{*}{ B.S. 2738} & Up to \pm 1.25 & 0.25 & 2.00 & 0.13 & 1.00 \\
\hline & Over \pm 2.50 & 0.13 & 0.50 & 0.13 & 0.50 \\
\hline ANSI & All & 0.66 & 2.50 & 0.33 & 1.00 \\
\hline ISO 16034:2002 & All & 0.33 & - & 0.33 & - \\
\hline
\end{tabular}

Source: (11) Jalie M. The Principles of Ophthalmic Lenses, 4th edn. London: The Association of Dispensing Opticians; 1984; Sonnier B, Coleman P, Murphy D., 2003. (15) Lensometry Prism Workshop. [Online] Available from: http://www.seco2011.com/presentation-pdfs/909.pdf [Accessed 31 July 2013]; International Organization for Standardization. (16) Ophthalmic optics - Specifications for single-vision ready-to-wear near-vision spectacles. In. ISO 16034:2002(en); 2002 
statistical analysis for the NIPDs of the sample as well as to form the basis for comparison with the average RMR OC distance. The RMR sample comprised 60 spectacles (30 for males and 30 for females) from five different suppliers based in China and Mauritius, all with similar retail prices. The optical centration data were obtained from a total of 60 RMRs with five RMRs selected per reading addition group. This was done in order to correspond with the respective six age group intervals (Table 2).

The power of the near-reading addition for presbyopic patients depends mostly on their age and their amplitude of accommodation. For the purpose of this study, six age group intervals were used and assigned to an expected reading addition power for the age groups 45-49 to 70-74 (six intervals). For a near-working distance of $33.33 \mathrm{~cm}$, the approximate spherical addition in dioptres (D) per age group was adapted from Emsley. ${ }^{21}$ Each RMR was placed in a Nikon PL-2 screen vertometer, and the RMR OC distances were marked. A PD rule was used to measure the distance between the OC distances of the lenses. Furthermore, an automatic LM 360 SPEXAN Lens Analyser was used to confirm the OC results obtained from the Nikon PL-2 screen vertometer.

Any differential vertical prism observed using the Nikon PL-2 was recorded. Such a prism occurs as a result of the difference in OC heights between the RMR lenses. The presence of any horizontally induced prism was calculated using Prentice's rule using the average near-IPD values for each population

TABLE 2: Expected reading addition per age group interval.

\begin{tabular}{lc}
\hline Presbyopic age group intervals & Expected near-reading addition (dioptres) \\
\hline Age group 40-44 & $0.50-0.75$ \\
Age group 45-49 & $1.00-1.25$ \\
Age group 50-54 & $1.50-1.75$ \\
Age group 55-59 & $2.00-2.25$ \\
Age group 60-64 & $2.50-2.75$ \\
Age group 65-69 & $3.00-3.25$ \\
Age group 70-74 & $3.50-3.75$ \\
Age group 75 and above & $>4.00$ \\
\hline
\end{tabular}

Source: Adapted from Emsley, 1976 group's age intervals and the individual RMR OC distance, which corresponded to those intervals in terms of addition power.

To evaluate the presence of optical strain, an optical polariscope was constructed by positioning two polarised filters at right angles to each other $\left(90^{\circ}\right)$. The strain pattern was observed when placing two fluorescent tubes underneath the test object, in order to provide back-illumination. A Nikon D70 SLR camera was employed to capture high-resolution images, whilst a 3.00-D lens was placed onto the planar filter lens of the camera to magnify the strain image. A template was constructed that was used to objectively analyse the strain patterns (Figure 1). The results were recorded according to the frequency of the strain pattern locations as well as the grading of severity per location.

Each lens image was divided into analysing quadrants Q1, Q2, Q3 and Q4 - and each quadrant was further divided into central, para-central, and peripheral areas. The nature of the strain was categorised according to mild, moderate and severe. Using this model, the analysis needed to take into account that both eyes view through the spectacles simultaneously. Consequently, the combined effects of the quadrants are recorded as follows: superior nasal RE Q1 corresponds to LE Q2, superior temporal RE Q2 corresponds to LE Q1, inferior temporal RE Q3 corresponds to LE Q4 and inferior nasal RE Q4 corresponds to LE Q3. The inferior nasal position is of specific importance because it reflects the area an RMR wearer views through when reading.

\section{Results \\ Near-inter-pupillary distance}

Measured averaged near-IPDs were $59.04 \mathrm{~mm}$ and $61.59 \mathrm{~mm}$ for the female and male patients, respectively. Descriptive statistics for the near-IPD data set, categorised according to the age group that corresponds to their appropriate addition power, is summarised in Table 3 .

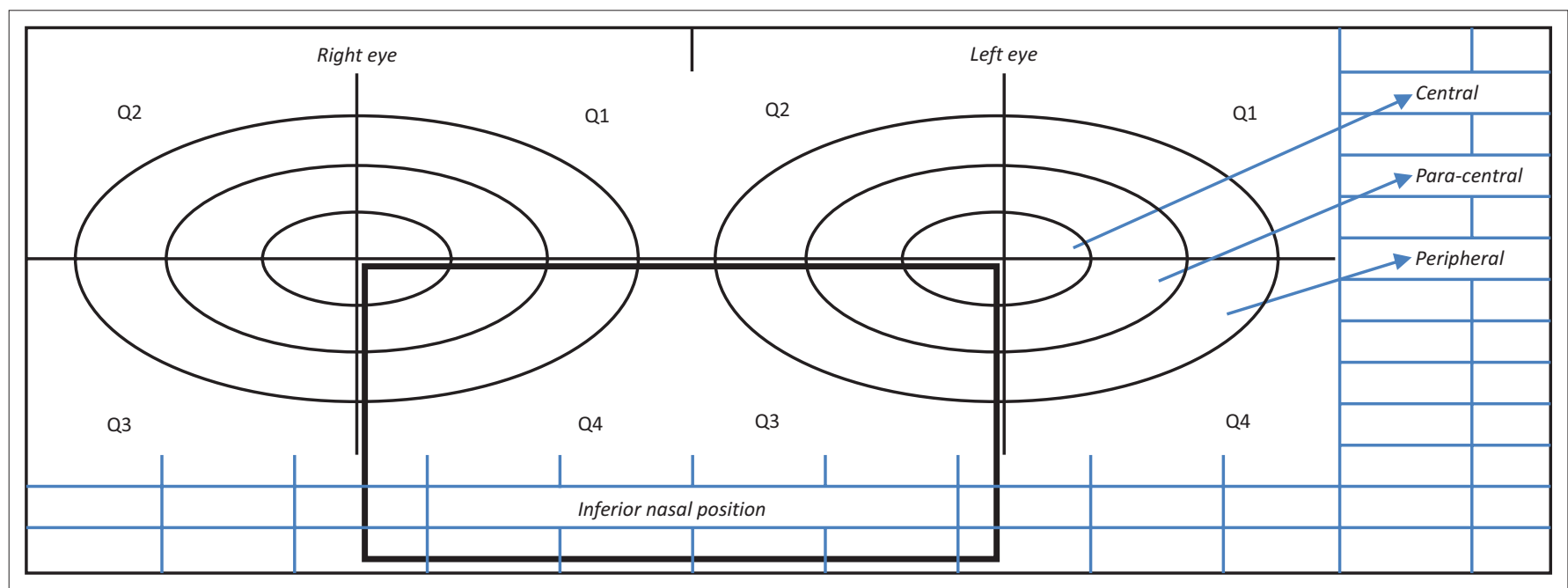

FIGURE 1: Combination grid used to analyse optical strain. 
TABLE 3: Near-inter-pupillary distance values per age group.

\begin{tabular}{llccc}
\hline Gender & Interval & $\begin{array}{c}\text { Number Px } \\
\text { per age group }\end{array}$ & $\begin{array}{c}\text { Average } \\
(\mathbf{m m})\end{array}$ & $\begin{array}{c}\text { s.d. } \\
(\mathbf{m m})\end{array}$ \\
\hline Female $^{\text {a }}$ & Age group 40-44 & 60 & 58.22 & 3.21 \\
& Age group 45-49 & 55 & 58.84 & 2.87 \\
& Age group 50-54 & 75 & 59.51 & 3.17 \\
& Age group 55-59 & 53 & 60.09 & 3.07 \\
& Age group 60-64 & 73 & 59.48 & 2.73 \\
& Age group 65-69 & 62 & 59.49 & 2.57 \\
& Age group 70-74 & 48 & 58.92 & 2.51 \\
Population average & Age group 75-79 & 37 & 58.29 & 2.33 \\
Male ${ }^{a}$ & Age group > 80 & 77 & 58.36 & 2.78 \\
& Age group 40-44 & 70 & 60.79 & 3.04 \\
& Age group 45-49 & 57 & 61.82 & 3.19 \\
& Age group 50-54 & 67 & 61.58 & 3.24 \\
& Age group 55-59 & 57 & 62.42 & 2.86 \\
& Age group 60-64 & 62 & 62.05 & 2.87 \\
& Age group 65-69 & 66 & 62.32 & 3.13 \\
& Age group 70-74 & 48 & 61.15 & 2.67 \\
& Age group 75-79 & 40 & 60.73 & 3.39 \\
& Age group > 80 & 64 & 61.29 & 3.01 \\
& - & - & 61.59 & $\mathbf{3 . 0 8}$ \\
\hline
\end{tabular}

s.d., standard deviation

a $n=540 ;$ female range $=51-69 ;$ female median $=59$. Male range $=51-71 ;$ male median $=61$

TABLE 4: Readymade reader optical centre distances for 60 readymade readers

\begin{tabular}{lccc}
\hline Gender & $\begin{array}{c}\text { Addition } \\
\text { power }\end{array}$ & $\begin{array}{c}\text { Average OC } \\
\text { distance }(\mathbf{m m})\end{array}$ & $\begin{array}{c}\text { s.d. } \\
(\mathbf{m m})\end{array}$ \\
\hline Female $^{\mathrm{a}}$ & 1.00 & 67.40 & 4.04 \\
& 1.50 & 67.20 & 2.68 \\
& 2.00 & 62.00 & 1.58 \\
& 2.50 & 62.80 & 1.79 \\
& 3.00 & 61.60 & 3.21 \\
Average & 3.50 & 66.00 & 4.18 \\
Male $^{\mathrm{a}}$ & - & 64.49 & $\mathbf{3 . 7 4}$ \\
& 1.00 & 62.20 & 1.10 \\
& 1.50 & 62.60 & 3.21 \\
& 2.00 & 63.20 & 1.79 \\
Average & 2.50 & 63.00 & 1.22 \\
\hline
\end{tabular}

OC, optical centre; RMR, readymade reader; s.d., standard deviation.

a, $n=30$; female range $=57-71$; female median $=63$. Male range $=58-67 ;$ male median $=63$.

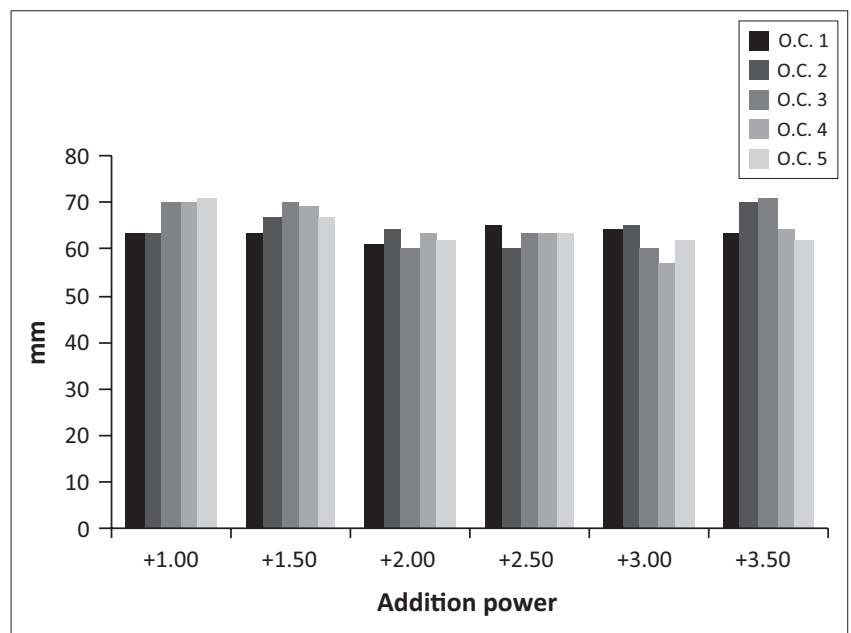

FIGURE 2: Female readymade readers optical centre distance measurements $(\mathrm{mm})$ for each addition power group (age interval).
The results for the RMR OC distances, classified according to addition power groups, are given in Table 4 and Figures 2,3 and 4 .

For the measurement of central tendency for the RMR OC distances, amongst the females this holds a statistically significant difference of tendency towards being positively skewed at $1.49 \mathrm{~mm}$. Males were less significant, with a negative skewed tendency of $-0.23 \mathrm{~mm}$. Figures 2 and 3 provides data for the $\mathrm{OC}$ centration distances corresponding to each additional power group.

Figure 4 provides summary data for male and female RMR OC distances corresponding to addition powers.

Figure 5 reflects the independent-samples $t$-test (95\% CI) for the near-IPD for female and male patients depicted against the corresponding RMR values. For the female patients, $t=-7.87 ; p<0.001$ and for the males, $t=-3.69$; $p<0.001$

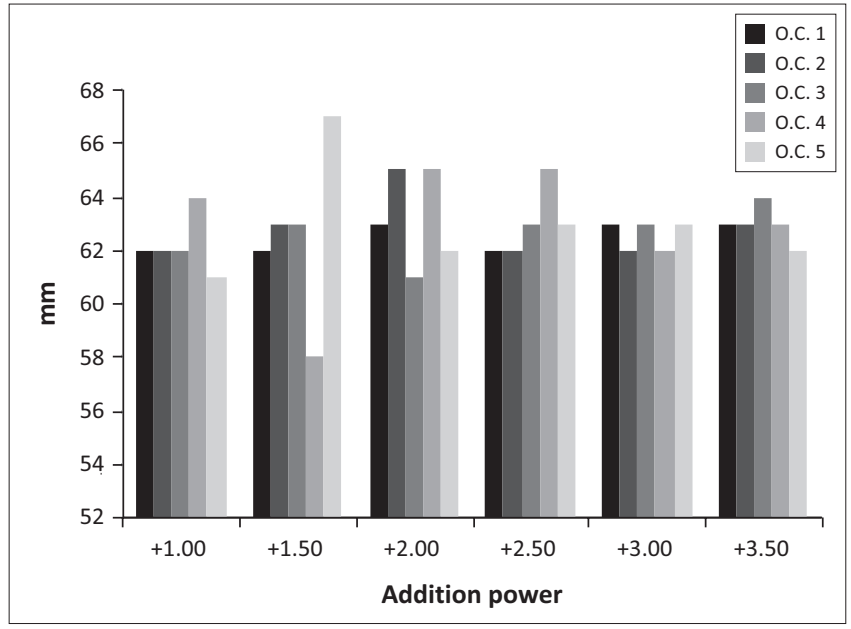

FIGURE 3: Male readymade readers optical centre distance measurements $(\mathrm{mm})$ for each addition power group (age interval).

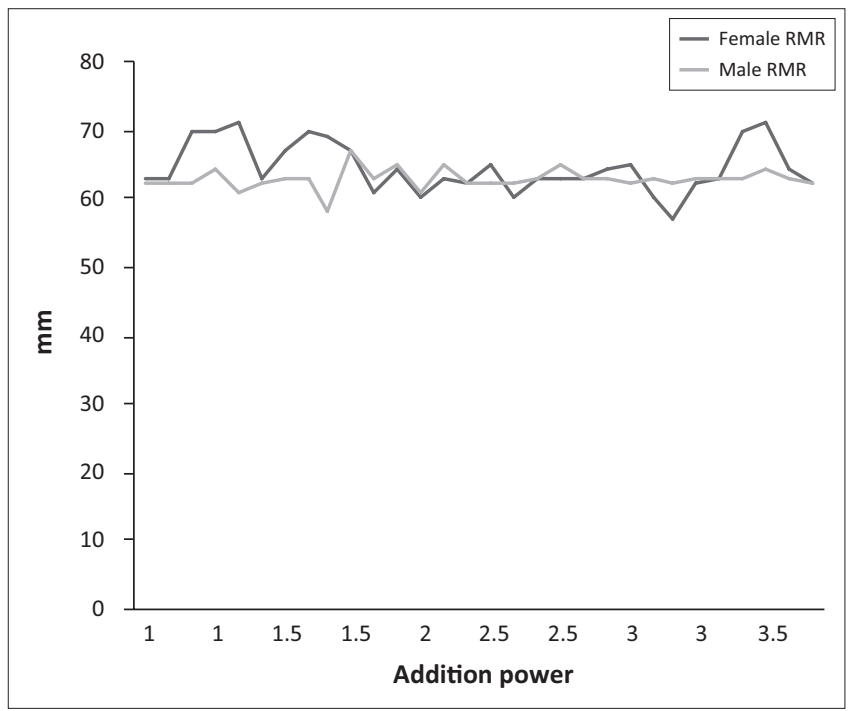

RMR, readymade reader.

FIGURE 4: Readymade readers optical centre distance measurements $(\mathrm{mm})$ for each addition power group (age interval). 


\section{Induced prismatic effect}

The vertically induced prismatic effect was measured in prism dioptres, and horizontally induced prismatic effect was calculated by Prentice's rule using the individual

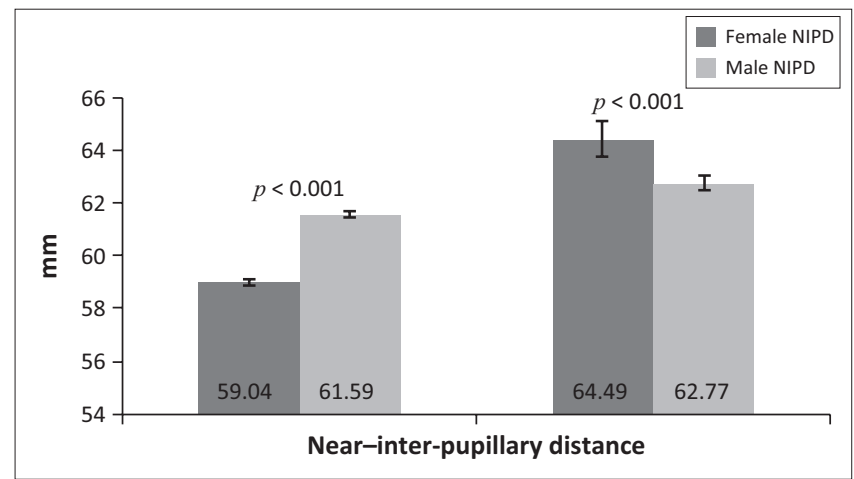

NIPD, near-inter-pupillary distance.

FIGURE 5: Comparison between patient inter-pupillary distance and the readymade readers optical centre distance.

TABLE 5: Vertically induced prismatic effect found in individual female and male readymade readers.

\begin{tabular}{lclllll}
\hline Gender & $\begin{array}{c}\text { RMR addition } \\
\text { power }\end{array}$ & \multicolumn{5}{c}{ Number of RMRs per addition group } \\
\cline { 3 - 7 } & & RMR 1 & RMR 2 & RMR 3 & RMR 4 & RMR 5 \\
\hline Female & 1.00 & $1.00 \mathrm{pd} \mathrm{BD}$ & Zero & Zero & Zero & Zero \\
RMRs & 1.50 & Zero & Zero & Zero & Zero & Zero \\
& 2.00 & Zero & Zero & Zero & Zero & Zero \\
& 2.50 & $0.50 \mathrm{pd} \mathrm{BU}$ & Zero & Zero & Zero & Zero \\
& 3.00 & Zero & Zero & Zero & Zero & Zero \\
& 3.50 & $0.50 \mathrm{pd} \mathrm{BD}$ & Zero & Zero & Zero & Zero \\
Male RMRs & 1.00 & $1.00 \mathrm{pd} \mathrm{BD}$ & Zero & Zero & Zero & Zero \\
& 1.50 & Zero & Zero & Zero & Zero & Zero \\
& 2.00 & $0.50 \mathrm{pd} \mathrm{BD}$ & $0.50 \mathrm{pd} \mathrm{BU}$ & Zero & Zero & Zero \\
& 2.50 & $1.00 \mathrm{pd} \mathrm{BD}$ & $0.50 \mathrm{pd} \mathrm{BU}$ & Zero & Zero & Zero \\
& 3.00 & $1.00 \mathrm{pd} \mathrm{BD}$ & $0.50 \mathrm{pd} \mathrm{BU}$ & $0.50 \mathrm{pd} \mathrm{BU}$ & Zero & Zero \\
& 3.50 & $0.50 \mathrm{pd} \mathrm{BD}$ & $0.50 \mathrm{pd} \mathrm{BU}$ & $1.00 \mathrm{pd} \mathrm{BU}$ & Zero & Zero \\
\hline
\end{tabular}

Note: The RMR sample group contained five RMRs per addition group. The number of RMR found to have vertical prism, together with the amount measured is indicated in the table. RMR, readymade reader.

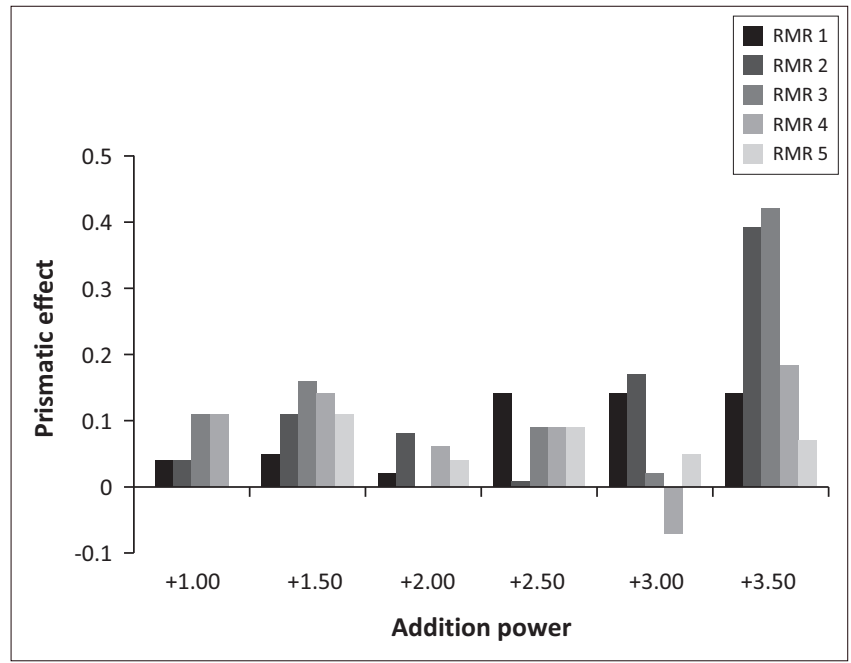

Note: Prism base-out is depicted as the + (positive) on the $y$-axis and prism base-in is depicted as - (negative) on the $y$-axis.

RMR, readymade reader.

FIGURE 6: Female horizontally induced prismatic effect for each addition power group (age interval).
RMR OC distance, which corresponded to the mean nearIPD intervals for that age group. The induced prismatic effects for RMRs for female and male patients are presented in Table 5 and in Figures 6, 7 and 8.

Based on the mean near-IPD and the corresponding RMR OC distance, the average horizontal prismatic effect found in female RMRs with induced prism was $0.11 \mathrm{pd}$ base-out (5.06 mm outwards) and $0.04 \mathrm{pd}$ base-in (1.26 mm inwards). For male patients, this was $0.03 \mathrm{pd}$ base-out $(1.32 \mathrm{~mm}$ outwards) and $0.02 \mathrm{pd}$ base-in (1.28 mm inwards) (Figure 8).

\section{Optical strain}

The presence of strain patterns was evaluated in a total of 120 RMR lenses. The strain patterns are recorded as a frequency in terms of location and severity in Table 6. Figure 9 provides an example of the observed strain.

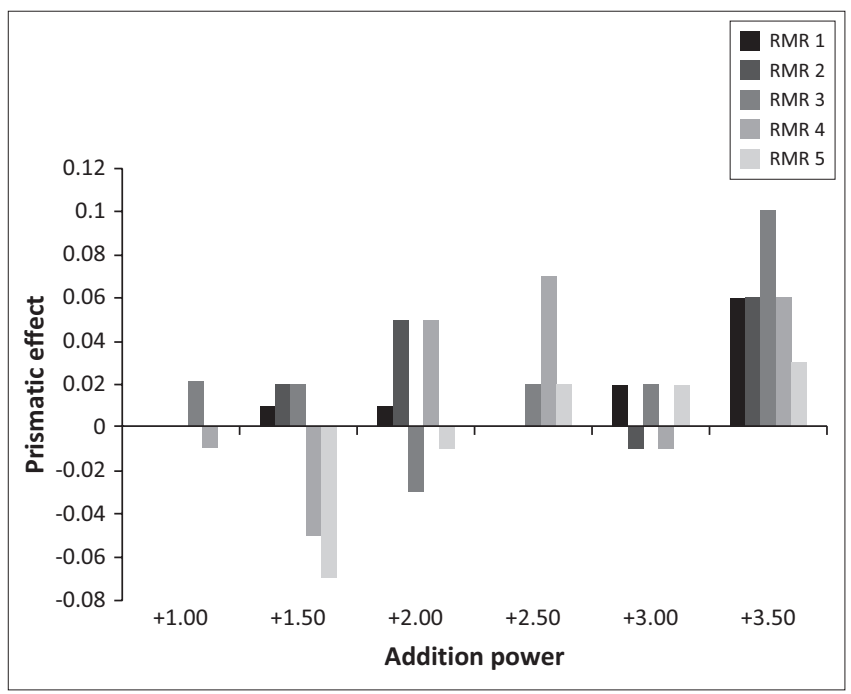

Note: Prism base-out is depicted as the + (positive) on the $y$-axis and prism base-in is depicted as - (negative) on the $y$-axis.

RMR, readymade reader.

FIGURE 7: Male horizontally induced prismatic effect for each addition power group (age interval).

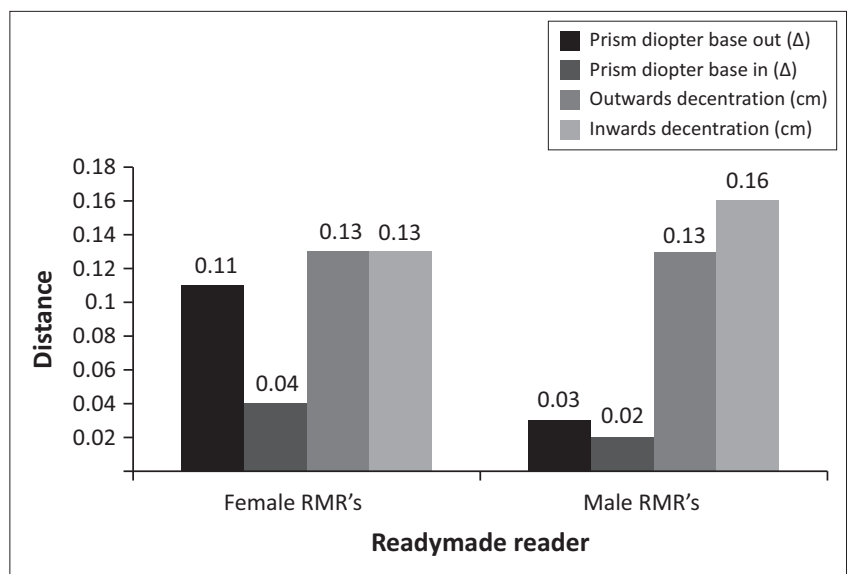

From left to right: $\mathrm{pd} \mathrm{BO}, \mathrm{pd} \mathrm{BI}$, outwards and inwards decentration $(\mathrm{cm})$. RMR, readymade reader.

FIGURE 8: Comparison between the average horizontal prismatic effect and the readymade readers optical centre distance decentration. 
TABLE 6: Frequency of strain observed in readymade readers.

\begin{tabular}{|c|c|c|c|c|c|c|c|c|c|c|}
\hline \multirow[t]{2}{*}{ Gender } & \multirow[t]{2}{*}{ Positions } & \multirow{2}{*}{$\begin{array}{c}\text { Number of } \\
\text { lenses per area }\end{array}$} & \multicolumn{4}{|c|}{ Location } & \multicolumn{4}{|c|}{ Grade } \\
\hline & & & Peripheral & Para-central & Central & Total & Mild & Moderate & Severe & Total \\
\hline \multirow[t]{5}{*}{ Female patients } & Superior nasal & 7 & 10 & 5 & 6 & 21 & 8 & 5 & 18 & 31 \\
\hline & Superior temporal & 10 & 12 & 7 & 4 & 23 & 13 & 4 & 13 & 30 \\
\hline & Inferior nasal & 10 & 27 & 18 & 10 & 55 & 22 & 15 & 37 & 74 \\
\hline & Inferior temporal & 13 & 34 & 21 & 6 & 61 & 26 & 13 & 40 & 79 \\
\hline & Frequency grand total & 40 & 83 & 51 & 26 & 160 & 69 & 37 & 108 & 214 \\
\hline \multirow[t]{5}{*}{ Male patients } & Superior nasal & 4 & 6 & 5 & 2 & 13 & 6 & 4 & 6 & 16 \\
\hline & Superior temporal & 9 & 13 & 7 & 2 & 22 & 15 & 3 & 8 & 26 \\
\hline & Inferior nasal & 8 & 18 & 5 & 3 & 26 & 12 & 4 & 16 & 32 \\
\hline & Inferior temporal & 13 & 20 & 10 & 4 & 34 & 14 & 7 & 22 & 43 \\
\hline & Frequency grand total & 34 & 57 & 27 & 11 & 95 & 47 & 18 & 52 & 117 \\
\hline
\end{tabular}

RMR, readymade reader.

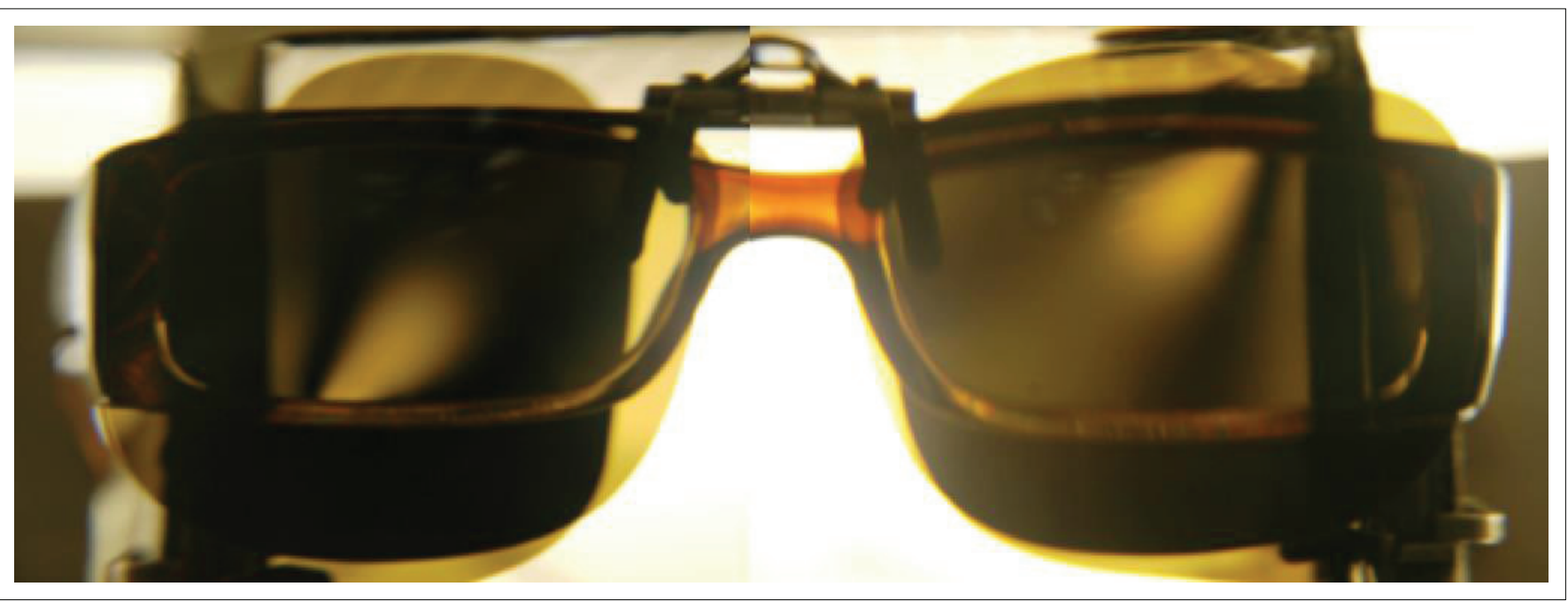

Source: Butler, MA

FIGURE 9: Observed strain.

\section{Discussion}

From the results, the measurement of central tendency for the near-IPD amongst the gender groups shows a small significance of tendency towards being negatively skewed at $-0.04 \mathrm{~mm}$ for females and $-0.59 \mathrm{~mm}$ for males. The study found that the average near-IPD was $59.04 \mathrm{~mm}$ for female and $61.59 \mathrm{~mm}$ for male patients. This is in line with a similar study conducted in the UK, ${ }^{5}$ which found values of $59.40 \mathrm{~mm}$ for female and $63.60 \mathrm{~mm}$ for male patients in a cohort of 200 people. Even closer alignment is found with a larger study also conducted by Pointer ${ }^{14}$ in the UK of 1354 North European Caucasian presbyopic subjects, where values of $59.31 \mathrm{~mm}$ for female and $62.22 \mathrm{~mm}$ for male subjects were obtained.

For the measurement of central tendency for the RMR OC distances, amongst the females this holds a statistically significant difference of tendency towards being positively skewed at $1.49 \mathrm{~mm}$. The results for the male patients were less significant, with a negative skewed tendency of $-0.23 \mathrm{~mm}$. An independent-samples $t$-test was conducted to investigate whether the means of the near-IPD and RMR OC distances were statistically different. The sample size was based on a 95\% CI; however, Figure 5 revealed significant difference at $99 \%$ CI. When comparing the average OC distance values for female $(64.49 \mathrm{~mm})$ and male $(62.77 \mathrm{~mm})$ RMRs to the corresponding average near-IPD values, there exists a difference of $5.45 \mathrm{~mm}$ (outwards) and $1.18 \mathrm{~mm}$ (outwards), respectively. This outward decentration would result in the majority of RMR wearers experiencing base-out prism (Figures 6 and 7). Pointer ${ }^{14}$ previously determined that an RMR OC distance of $60.00 \mathrm{~mm}$ would be optimal for reducing horizontally induced prismatic effect, but a further study by Elliot et al. ${ }^{5}$ recommended a value of $61.00 \mathrm{~mm}$ for Caucasian people of Northern Europe. Our study supports the latter as the average of the combined female and male IPDs was found to be $60.76 \mathrm{~mm}$.

The induced prismatic effects were compared to three international standards, namely British Standards (B.S.2738), ANSI and ISO (16034:2002). A summary of the values found compared to these standards is depicted in Table 7.

Overall, the B.S.2738 standard is stricter than ANSI and ISO, which resulted in $20 \%$ of female RMRs above $2.50 \mathrm{D}$ being outside of the horizontally induced tolerances. The average vertically induced prismatic effect recorded for RMRs for female patients was $0.67 \mathrm{pd}(10.00 \%)$ and that for male patients was $0.68 \mathrm{pd}(36.67 \%)$. The main consequence of this misalignment of the OCs with the patient near-IPD would be undesirable prismatic effects. In terms of clinical tolerance, $\mathrm{du}$ Toit et al. ${ }^{9}$ estimated that most spectacle wearers would 
TABLE 7: Summary data of 60 readymade readers compared to international standards (tolerances).

\begin{tabular}{|c|c|c|c|c|}
\hline Standard type & Addition power & $\begin{array}{l}\text { Tolerance (pd base-in } \\
\text { and base-out) }\end{array}$ & $\begin{array}{c}\text { Average prism } \\
\text { for female RMRs }\end{array}$ & $\begin{array}{l}\text { Average prism } \\
\text { for male RMRs }\end{array}$ \\
\hline Horizontally induced prism & - & - & - & - \\
\hline \multirow[t]{3}{*}{ B.S.2738 } & Up to +1.25 & 0.25 & $0.06 \mathrm{pd} \mathrm{BO}$ & $0.01 \mathrm{pd} \mathrm{BO}$ \\
\hline & +1.25 to +2.50 & 0.25 & $0.08 \mathrm{pd} \mathrm{BO}$ & $0.03 \mathrm{pd} \mathrm{BO}$ \\
\hline & Over +2.50 & 0.13 & $0.16 \mathrm{pd} \mathrm{BO}$ & $0.04 \mathrm{pd} \mathrm{BO}$ \\
\hline ANSI & All & 0.66 & $0.10 \mathrm{pd} \mathrm{BO}$ & $0.03 \mathrm{pd} \mathrm{BO}$ \\
\hline ISO $16034: 2002$ & All & 0.33 & $0.10 \mathrm{pd} \mathrm{BO}$ & $0.03 \mathrm{pd} \mathrm{BO}$ \\
\hline Horizontally induced decentration & - & - & - & - \\
\hline \multirow[t]{3}{*}{ B.S. 2738} & Up to +1.25 & 2 & 6.13 Outwards & 0.71 Outwards \\
\hline & +1.25 to +2.50 & 1.00 & 3.21 Outwards & 1.59 Outwards \\
\hline & Over +2.50 & 0.5 & 4.89 Outwards & 1.19 Outwards \\
\hline ANSI & All & 2.5 & 4.81 Outwards & 1.31 Outwards \\
\hline ISO 16034:2002 & All & $\mathrm{n} / \mathrm{a}$ & $n / a$ & $\mathrm{n} / \mathrm{a}$ \\
\hline Vertically induced prism & - & - & - & - \\
\hline \multirow[t]{3}{*}{ B.S. 2738} & Up to +1.25 & 0.13 & 1 & 1 \\
\hline & +1.25 to +2.50 & 0.13 & 0.5 & 0.63 \\
\hline & Over +2.50 & 0.13 & 0.5 & 0.67 \\
\hline ANSI & All & 0.33 & 0.67 & 0.68 \\
\hline ISO 16034:2002 & All & 0.33 & 0.67 & 0.68 \\
\hline
\end{tabular}

RMR, readymade reader.

likely comfortably tolerate up to $0.5 \mathrm{pd}$ vertical prism, $1.0 \mathrm{pd}$ prism base-out or $1.0 \mathrm{pd}$ base-in induced prism. In this study, none of the RMRs were found to exhibit horizontally induced prism greater than the suggested guidelines. However, the vertically induced prism for RMRs for both the male and female patients was found to exceed both international standards as well as the clinically accepted tolerances suggested by du Toit et al. ${ }^{9}$ It would be expected that if patients were to wear RMRs with such vertically induced prismatic effects, symptoms such as nausea, blurred or distorted vision, headache, disorientation and discomfort may be experienced.

A review of the available literature found no published research on the effects of optical strain and visual fatigue. In this study, optical strain was observed in RMR lenses in $66.67 \%$ and $56.67 \%$ for the female and male patients, respectively. The strain pattern was found to be most severe in the inferior temporal periphery for 34 female and 20 male frequencies, followed by the inferior nasal periphery for 27 and 18 female and male frequencies, respectively. The inferior nasal periphery area is of particular importance because it is the area through which patients view when looking down to read. In agreement with Elliott et al., ${ }^{5}$ this optical defect could result in the RMR wearer experiencing effects such as blurred vision, tired eyes after prolonged use, asthenopia, mild vertigo or dizziness, micropsia, macropsia and/or diplopia. This may, in fact, be an even more important consideration than the induced prismatic effects because it may directly affect the wearer's visual acuity and ocular comfort.

\section{Recommendations and conclusion}

In order to produce appropriate RMRs, this study recommends that RMR manufacturers should attempt to align manufacturing specifications of the RMR OC distance with the average near-IPDs found in this study. The suggested RMR OC distance of $59.00 \mathrm{~mm}$ for female and $62.00 \mathrm{~mm}$ for male patients would be a suitable centration to ensure that for this population group the induced prismatic effect is minimal. Should Unisex RMRs be manufactured, a compromise OC distance of $61.00 \mathrm{~mm}$ would be appropriate. This study found that the sample of RMRs exhibited vertical prism well above the international standards, and this induced prismatic effect cannot be comfortably tolerated. It would be important for this aspect to be addressed by manufacturers to ensure compliance with standards as well as visual comfort for the wearer's. Optical strain could be eliminated through accurate glazing in order to reduce excessive pressure on the lenses as well as through improved injection moulding or surfacing procedures. Stricter quality control should be ensured through all stages of production. It would not be expected that these recommendations would add significantly to the production costs.

The use of readily available and affordable RMRs furthermore supports the feasibility of using RMRs in low-resource settings. ${ }^{9}$ Once shortcomings in terms of vertical centration and strain are addressed, such spectacles could provide much needed assistance. Both in South Africa and internationally, there are millions in need of optical correction for near-vision. Production of quality RMRs would help to alleviate the global burden of uncorrected presbyopia and afford patients the opportunity to perform near-tasks both at work and in the home environment. Further resources would be needed to determine whether the optical strain found in existing RMRs would pose a significant impact on vision in such populations. It is important to stress, however, that even though it may be safe to use RMRs for near-vision tasks, it remains critically important to first have one's eyes examined regularly to rule out sight-threatening diseases such as glaucoma, cataract, macula degeneration and diabetic retinopathy. ${ }^{22}$

There is a definite role and value to RMRs as they provide an affordable and accessible means for correcting presbyopia. They also have a role to play as a spare pair of spectacles for 
all presbyopic patients across all socio-economic groups, and in the primary health environment, RMRs may be used as an interim means of correction following cataract surgery. In optometric practices, one should consider the PD of patients before dispensing so as to prescribe RMR OC that are as near as possible to the patients PD. Considering all the possible and widespread uses for these spectacles, the study recommends that the optical quality, clarity and appropriate centration distances are strictly controlled for the benefit of the patient.

\section{Acknowledgements}

The authors thank Mr S Abramson, Mr R van Gijsen and Mr N Burger for their valuable support.

\section{Competing interests}

The authors declare that they have no financial or personal relationships which may have inappropriately influenced them in writing this article.

\section{Authors' contributions}

M.A.B. was the principle investigator; M.E.J. was responsible for the literature review and referencing and P.C.C-F. for the supervision and write-up.

\section{References}

1 Holden BA, Fricke TR, Ho SM, Wong R, Schlenther G, Cronje S, Burnett A, Papas E, Naidoo KS, Frick KD. Global vision impairment due to uncorrected presbyopia. Arch Ophthalmol. 2008;126:1731-1739.

2 Patel I, Munoz B, Burke AG, Kayongoya A, McHiwa W, Schwarzwalder AW, West SK. Impact of presbyopia on quality of life in a rural African setting. Ophthalmol. 2006;113:728-734.

3 Shane TS, Knight O, Shi W, Schiffman JC, Alfonso EC, Lee RK. Treating uncorrected refractive error in adults in the developing world with autorefractors and ready-made spectacles. Clin Exper Ophthalmol. 2011;39:729-733.
4 Hookway LA, Fuhr P, Frazier M. Use of ready-made spectacles to meet visual needs in a low-resource adult population. Optom Vis Sci. 2013;90:494-500.

5 Elliott DB, Green A. Many ready-made reading spectacles fail the required standards. Optom Vis Sci. 2012;89:E446-E451.

6 West CE, Hunter DG. Displacement of optical centers in over-the-counter readers: A potential cause of diplopia. J Am Assoc Pediatric Ophthalmol Strab. 2014;18:293-294.

7 Ramke J, Palagyi A, Toit R, Brian G. Applying standards to readymade spectacles used in low-resource countries. Optom Vis Sci. 2009;86:1104-1111.

8 Gupta VP, Sodhi PK, Pandey RM. Normal values for inner intercanthal, interpupillary, and outer intercanthal distances in the Indian population. Int I Clin Prac. 2003;57:25-29.

9 Du Toit R, Ramke J, Brian G. Tolerance to prism induced by readymade spectacles: Setting and using a standard. Optom Vis Sci. 2007;84:1053-1059.

10 Moodley VR, Kadwa F, Nxumalo B, Penceliah S, Ramkalam B, Zama A. Induced prismatic effects due to poorly fitting spectacle frames. S Afr Optom. 2011;70: 168-174.

11 Jalie M. The principles of ophthalmic lenses. 4th ed. London: The Association of Dispensing Opticians; 1984.

12 Jimenez JR, Rubino M, Diaz JA, Hita E, del Barco LJ. Changes in stereoscopic depth perception caused by decentration of spectacle lenses. Optom Vis Sci. 2000; 77:421-427.

13 Dodgson NA. Variation and extrema of human inter-pupillary distance. In Woods AJ, Merritt JO, Benton SA, Bolas MJ, editors. Stereoscopic displays and virtual reality XI. Proceedings of SPIE 5291; 2004 Jan 19-22; San Jose, CA. Society of Photo-Optical Instrumentation Engineers; 2004. pp. 36-46.

14 Pointer JS. The inter-pupillary distance in adult Caucasian subjects, with reference to 'readymade' reading spectacle centration. Ophthal Physiol Opt. 2012;32:324-331.

15 Sonnier B, Coleman P, Murphy D. Lensometry Prism Workshop. 2003 [cited 2013 Jul 31]. Available from: http://www.seco2011.com/presentation-pdfs/909.pdf

16 International Organization for Standardization. Ophthalmic optics - Specifications for single-vision ready-to-wear near- vision spectacles. ISO 16034:2002(en); 2002.

17 Brian G, du Toit R, Wilson D, Ramke J. Affordable ready-made spectacles for use in blindness prevention programmes: Setting standards of quality. Clin Exp Ophthalmol. 2006;34:722-724.

18. City of Cape Town. City of Cape Town 2011 Census Suburb Sea Point. 2013 [cited 2015 Jun 2]. Available from: https://www.capetown.gov.za/en/stats/ 2011CensusSuburbs/2011_Census_CT_Suburb_Sea_Point_Profile.pdf

19 Creative Research Systems. Sample size calculator. 2012 [cited 2013 Aug 26]. Available from: http://www.surveysystem.com/sscalc.htm\#two 20 StatsSA. Midyear population estimates by province. 2011 [cited 2013 Aug 26]. Available from: http://www.statssa.gov.za/publications/P0302/P03022011.pdf

21 Emsley HH. Visual optics. 5th ed. London: Butterworths; 1976.

22 Phillips KC, Clarke-Farr PC. Practitioners opinion on the presentation of ocular pathology and ametropia in patients wearing ready-made reading spectacles. S Afr Optom. 2008;67:125-135. 